\title{
Use of selective serotonin-reuptake inhibitors during early pregnancy and risk of congenital malformations: updated analysis
}

This article was published in the following Dove Press journal:

Clinical Epidemiology

13 March 2010

Number of times this article has been viewed

\author{
Jette B Kornum' \\ Rikke B Nielsen' \\ Lars Pedersen' \\ Preben B Mortensen ${ }^{2}$ \\ Mette Nørgaard' \\ 'Department of Clinical Epidemiology, \\ Aarhus University Hospital, Denmark; \\ ${ }^{2}$ National Center for Registry-based \\ Research, University of Aarhus, \\ Aarhus, Denmark
}

Background: Data on the safety of selective serotonin-reuptake inhibitors (SSRIs) in pregnancy are inconsistent. We examined associations between SSRI use during early pregnancy and risk of congenital malformations in infants.

Methods: Set in Northern Denmark, our population-based prevalence study included 216,042 women who had a live birth after the 20th week of gestation. We compared the prevalence of malformation in infants born to women who redeemed at least one SSRI prescription during early pregnancy with the prevalence in infants born to women who redeemed no SSRI prescriptions during their pregnancies. Drug use data were extracted from prescription databases, while data on congenital malformations were obtained from the National Registry of Patients.

Results: The 2,062 women with SSRI prescriptions during early pregnancy gave birth to 105 (5.1\%) infants with malformations, while the 213,712 women with no SSRI prescriptions gave birth to $7,449(3.5 \%)$ infants with malformations. SSRI use was associated with an increased risk of malformations overall (odds ratio $[\mathrm{OR}]=1.3 ; 95 \%$ confidence interval $(\mathrm{CI})$ : 1.1-1.6) and cardiac malformations (OR $=1.7$; 95\% CI: 1.1-2.5). For specific SSRIs, we found an increased risk for septal defects associated with sertraline.

Conclusions: We found little overall association between use of SSRIs during pregnancy and congenital malformations, but our findings suggest an association between maternal SSRI use in early pregnancy and cardiac malformations which could be causal.

Keywords: antidepressants, drug safety, pregnancy, congenital malformations, epidemiology

\section{Introduction}

Selective serotonin-reuptake inhibitors (SSRIs), the first-line pharmacotherapy for depression, represent the most frequently used antidepressant among pregnant women. ${ }^{1-3}$ Between $2 \%$ and $13 \%$ of all pregnant women are treated with antidepressants ${ }^{1-3}$ and use of SSRIs during pregnancy has increased two- to fourfold in western populations during the last decade..$^{2-4}$

SSRIs readily cross the placenta ${ }^{5,6}$ and concerns have been raised about their safety in pregnancy, including the risk of low birth weight, prematurity, low Apgar score, and persistent pulmonary hypertension in the newborn. ${ }^{7}$ Maternal SSRI use during pregnancy also has been associated with an almost twofold increased risk of congenital malformations overall, ${ }^{8-10}$ but existing studies have yielded divergent results. ${ }^{8-17}$ Furthermore, maternal SSRI use have been associated with the risk of congenital cardiac malformations in some ${ }^{8,12,16,18-21}$ but not all studies, ${ }^{11,22}$ and with the risk of omphalocele, anencephaly, and craniosynostosis. ${ }^{22}$ The discrepancies may stem from
Correspondence: Jette B Kornum Department of Clinical Epidemiology, Sdr. Skovvej I5, DK-9100 Aalborg, Denmark Tel +459932 6910

Fax +4599326914

Email j.kornum@rn.dk 
methodological differences. For instance some studies are studies based on data from Teratogen Information Service centers, which offer advice to women, who request counselling about the teratogenic potential of SSRIs. ${ }^{13,15,21}$ These women are thus included based on self-referral, which may threaten the validity. Others are retrospective case-control studies based on interviews or questionnaires with the risk of recall bias and skewed data due to a high proportion of nonresponders, ${ }^{19,22}$ and some are based on linkage between large administrative registers. ${ }^{8-12,20}$ Since specific SSRIs do not share chemical structures and pharmacokinetic properties, ${ }^{23}$ they could have different teratologic effects. Paroxetine has been associated with a 1.7-fold increased risk of cardiac malformations in a recent meta-analysis. ${ }^{18}$ However, relatively few studies have assessed the risk of malformation associated with use of other specific SSRIs, and their results are inconsistent. ${ }^{12,16,19-22}$

Because of the increasing use of SSRI during pregnancy and the fact that untreated depression during pregnancy can have adverse effects on the mother and her child, ${ }^{24,25}$ it is important to clarify whether maternal SSRI use increases the risk of congenital malformations and to identify the specific SSRIs associated with the highest risk. We therefore updated a previous analysis ${ }^{9}$ to examine the associations between SSRI use during early pregnancy and overall risk of congenital malformations and risk of cardiac malformations in infants.

\section{Methods}

\section{Setting and study population}

We conducted this population-based prevalence study in a population of 1.6 million from Northern Denmark (approximately $31 \%$ of the Danish population). We used data from the counties' computerized prescription registries during three time periods, corresponding to the dates of data availability in the counties; 1991-2007 (North Jutland County), 1996-2007 (Aarhus County), and 1998-2007 (Ringkjøbing and Viborg Counties). Our study included all women in the counties who had a live birth after the 20th week of gestation during the periods covered by the prescription registries. The women were identified through the Danish Medical Birth Registry, which contains information on all births in Denmark since January $1973 .{ }^{26}$ The main variables in the registry include maternal age, parity, birth weight, gestational age, maternal smoking status during pregnancy, citizenship, data on delivery, and information on multiple pregnancy. We used the unique civil registration number assigned to all Danish residents at birth or upon immigration to link the prescription records with data from the Danish Medical Birth Registry and the National Registry of Patients.

\section{Data on antidepressants and other drugs}

The Danish National Health Service reimburses part of patient expenditures for numerous prescribed medicines including SSRIs. The four counties are served by pharmacies equipped with electronic accounting systems that track data on all prescriptions on reimbursable medicines including the patients' civil registration number, type of drug prescribed according to the Anatomical Therapeutic Chemical (ATC) classification system, amount prescribed, and the date the drug was dispensed. All data are transferred to a research database at Aarhus University Hospital. In Denmark, SSRIs may be obtained from pharmacies only with a prescription from a medical doctor. ATC codes for specific SSRIs are citalopram (N06A B04), sertraline (N06A B06), fluvoxamine (N06A B08), fluoxetine (N06A B03), paroxetine (N06A B05), and escitalopram (N06A B10). We obtained data on all prescriptions for a SSRI redeemed by women in our study cohort from 30 days before conception until the end of each pregnancy.

Finally, we also retrieved data on prescriptions for non-SSRI antidepressants (N06AA, NO6AF, N06AG, N06AX) to examine the risk of congenital malformations after maternal use of these alternative medications. We excluded women who redeemed prescriptions for both a SSRI and a non-SSRI antidepressants in the period from 30 days before conception until the end of each pregnancy.

\section{Outcome data}

Data on congenital malformations were obtained from the National Registry of Patients. This registry, established in 1977, includes dates of admission and discharge, surgical procedures performed, and up to 20 discharge diagnoses coded by physicians according to the International Classification of Diseases, 8th revision (ICD-8) until the end of 1993 and 10th revision (ICD-10) thereafter. The following codes were used to identify malformations: malformations overall (ICD-8: 740-759, except 747.0 and ICD-10: Q00-Q99, except Q25.0); cardiac malformations overall (ICD-8: 746.0-746.6, 746.8-746.9, 747.1-747.4 and ICD-10: Q20.0-Q20.6, Q20.8-Q20.9, Q21.0-21.4, Q21.821.9, Q22.0-22.9, Q23.0-23.9, Q24.0-24.9, Q25.1-25.9, Q26.0-26.4, Q26.8-26.9), and septal defects (ICD-8: 746.2-746.4 and ICD-10: Q21.0-Q21.4, Q21.8-Q21.9). To standardize the period of observation, we included only malformations registered during the first year of life. 
We excluded diagnoses of congenital dislocations of the hip (ICD-8 code 755.69 and ICD-10 codes Q65.0-65.6) and undescended testes (ICD-8 codes 752.10-752.11, 752.19 and ICD-10 code Q53) due to the poor validity of these diagnoses. ${ }^{27}$ We also excluded women who had a multiple birth or whose infants had chromosomal defects. The following procedure codes were used to identify infants, who had had heart surgery, or catheter-based therapeutic interventions performed during their first year of life: 30500-32990 and KFA-KFX.

\section{Data on potential confounders}

Because diabetes and use of antiepileptics have been associated with an increased risk of congenital malformations, ${ }^{28,29}$ we excluded women who used antiepileptics (ATC code N03A) during the first trimester of pregnancy or 90 days before conception or who used antidiabetic drugs (ATC code A10) at any time before conception or during the entire pregnancy. Data on other potential confounders, including maternal age, birth order, and maternal smoking status, were obtained from the Danish Medical Birth Registry.

\section{Statistical analysis}

We used logistic regression to compute crude and adjusted prevalence odds ratios (ORs) with associated 95\% confidence intervals (CIs) for congenital malformations overall among women who redeemed any SSRI prescription in early pregnancy (from 30 days before conception until the end of the first trimester) and among women who redeemed a SSRI prescription in the second or third month of pregnancy, which is the most critical period for development of malformations. The comparison group consisted of women who did not redeem a SSRI prescription in the period from 30 days before conception to the end of pregnancy. We adjusted for maternal smoking during pregnancy (smoker, nonsmoker), birth order $(1,>1)$, maternal age (as a continuous variable), and birth year (1991-1994, 1995-1998, 1999-2002, 2003-2007).

We examined four categories of malformations: malformations overall, noncardiac malformations, cardiac malformations, and septal defects diagnosed within the infant's first year of life. We then computed ORs for these outcomes associated with SSRI use overall, with use of individual SSRIs, and with use of non-SSRI antidepressants in early pregnancy. Because the occurrence of a malformation may change prescription practice in a subsequent pregnancy, we also examined the association between SSRI use and malformations among firstborn infants only.
In a separate analysis, we extended the follow-up-period and examined the association between use of SSRIs and cardiac malformations diagnosed within the infants first three years of life.

We addressed whether a possible association between SSRI use and congential malformations could be explained by the underlying disease for which SSRIs were prescribed or by disease-related behavioral factors. In subanalyses we examined the association between SSRI exposure and congenital malformations in women who redeemed an SSRI prescription six months before conception up to 30 days before conception, and in women who redeemed an SSRI prescription in their second or third trimester. The comparison group for these analyses consisted of women who did not redeem any SSRI prescriptions before giving birth.

Finally, to address whether any association between SSRI use and cardiac malformations could be explained by increased surveillance of SSRI-exposed infants, we analyzed the association between maternal SSRI use and risk of cardiac malformation restricting the outcome to infants who had heart surgery, or catheter-based therapeutic interventions performed during their first year of life.

We analyzed data using SAS software (version 9.2; SAS Institute, Cary, NC, USA). The Danish Registry Board approved the study (record no. 2002-41-1820).

\section{Results}

\section{Descriptive data}

Among the 216,042 women who had a live birth during the study period, a total of 2,062 (1.0\%) redeemed a prescription for an SSRI in early pregnancy (from 30 days before conception until the end of the first trimester) and $931(0.4 \%)$ redeemed a prescription during the second or third month of pregnancy. Compared with women without SSRI prescriptions during the entire pregnancy, those with SSRI prescriptions tended to be slightly older (median age 30.5 years vs 29.8 years) and were more likely to be smokers, and to have preterm delivery (defined as delivery $<37$ gestational weeks) (Table 1). The most common SSRI and combinations of SSRIs prescribed to women during early pregnancy are shown in Table 2. The women who used combinations of SSRI, except in four cases, redeemed the different types of SSRIs on different dates.

\section{SSRI use and congenital malformations overall}

Among the infants of the 2,062 women who redeemed a SSRI prescription any time during early pregnancy, 
Table I Characteristics of women with and without prescriptions for selective serotonin-reuptake inhibitors (SSRIs)

\begin{tabular}{|c|c|c|c|}
\hline & \multicolumn{2}{|l|}{ SSRI prescriptions redeemed } & \multirow{2}{*}{$\begin{array}{l}\text { No prescriptions for SSRIs } \\
\text { during the entire pregnancy } \\
\text { or } 30 \text { days before conception } \\
\text { No }(\%)(n=2|3,7| 2)\end{array}$} \\
\hline & $\begin{array}{l}\text { Within first trimester or } 30 \text { days } \\
\text { before conception No (\%) } \\
(n=2,062)\end{array}$ & $\begin{array}{l}\text { Within second or third month } \\
\text { after conception No }(\%)(n=931)\end{array}$ & \\
\hline \multicolumn{4}{|l|}{ Maternal age (years) } \\
\hline$\leq 19$ & $27(1.3)$ & $7(0.8)$ & $3,074(1.4)$ \\
\hline $20-24$ & $265(12.9)$ & $113(12.1)$ & $26,426(12.4)$ \\
\hline $25-29$ & $660(32.0)$ & $284(30.5)$ & $80,649(37.7)$ \\
\hline $30-34$ & $676(32.8)$ & $315(33.8)$ & $72,857(34.1)$ \\
\hline$\geq 35$ & $434(21.0)$ & $212(22.8)$ & $30,706(14.4)$ \\
\hline \multicolumn{4}{|l|}{ Parity } \\
\hline 1 & $872(42.3)$ & $406(43.6)$ & $88,980(41.6)$ \\
\hline$>1$ & $\mathrm{I}, 190(57.7)$ & $525(56.4)$ & $124,732(58.4)$ \\
\hline \multicolumn{4}{|l|}{ Birth year } \\
\hline $199 \mid-1994$ & $4(0.2)$ & $2(0.2)$ & $|7,50|(8.2)$ \\
\hline $1995-1998$ & $112(5.4)$ & $21(2.3)$ & $38,570(18.0)$ \\
\hline 1999-2002 & $509(24.7)$ & $165(17.7)$ & $71,863(33.6)$ \\
\hline $2003-2007$ & I,437 (69.7) & $743(79.8)$ & $85,778(40.1)$ \\
\hline \multicolumn{4}{|c|}{ Maternal smoking status } \\
\hline No & $1,263(61.3)$ & $602(64.7)$ & $|64,77|(77.1)$ \\
\hline Yes & $739(35.8)$ & $296(31.8)$ & $43,98 \mid(20.6)$ \\
\hline Missing & $60(2.9)$ & $33(3.5)$ & $4,960(2.3)$ \\
\hline $\begin{array}{l}\text { Infants with congenital } \\
\text { malformations }\end{array}$ & $105(5.1)$ & $42(4.5)$ & 7,449 (3.5) \\
\hline $\begin{array}{l}\text { Infants with congenital } \\
\text { cardiac malformations }\end{array}$ & $26(1.3)$ & II (I.2) & $\mathrm{I}, 403(0.7)$ \\
\hline \multicolumn{4}{|l|}{ Gestational age } \\
\hline$\leq 31$ & $20(1.0)$ & $10(1.1)$ & I,439 (0.7) \\
\hline $32-36$ & $122(5.9)$ & $65(7.0)$ & $8,675(4.1)$ \\
\hline$\geq 37$ & I,920 (93.I) & 856 (91.9) & $203,598(95.3)$ \\
\hline
\end{tabular}

$105(5.1 \%)$ infants had congenital malformations compared with a prevalence of $3.5 \%$ among the unexposed. Among infants of women with SSRI prescriptions during early pregnancy, a total of 104 different malformation diagnoses were recorded, including 88 noncardiac diagnoses. The most frequently recorded malformation diagnoses were atrial septal defect $(n=11)$, ventricular septal defect $(n=10)$, congenital malformation unspecified $(n=8)$, congenital cardiac malformation, unspecified $(n=7)$ stenosis of pulmonary artery $(n=5)$, congenital hydronephrosis $(n=5)$, and plagiocephaly $(n=5)$. Other malformations had fewer than five records. Table 3 shows the absolute number and prevalence of infants with any malformation, noncardiac malformation, cardiac malformation, and septal heart defect according to maternal use of different types of antidepressants.

Redemption of any SSRI prescription in early pregnancy was associated with a 1.3-fold (95\% CI: $1.1-1.6)$ increased risk of malformations overall (Table 4). The corresponding OR was 1.2 (95\% CI: 0.9-1.6), when we repeated the analysis in firstborn infants only. For noncardiac malformations, the adjusted OR was 1.2 (95\% CI: 1.0-1.6) (Table 4). Redemption of any SSRI prescription during the second or third month of pregnancy was associated with a 1.1 -fold $(95 \% \mathrm{CI}$ : 0.8-1.6) increased risk of malformations overall.

For several of the individual SSRIs we found an increased risk of congenital malformations overall following use in early pregnancy (Table 4). However, our confidence intervals are wide and they all include 1.0 (Table 4).

We identified 1,226 women who redeemed SSRI prescriptions from six months to 30 days before conception (but not during pregnancy) and 266 women who redeemed SSRI prescriptions during their second or third trimester. The adjusted OR for malformations overall was 1.1 (95\% CI: 0.8-1.4) for SSRI use in the period from six months to 
Table 2 Number and percent of women who redeemed one or more prescriptions for specific selective serotonin-reuptake inhibitors (SSRIs) or combinations of SSRls during early pregnancy

\begin{tabular}{ll}
\hline Drug & Number (\%) \\
\hline Citalopram & $658(31.9)$ \\
Fluoxetine & $472(22.9)$ \\
Sertraline & $352(17.1)$ \\
Paroxetine & $297(14.4)$ \\
Escitalopram & $88(4.3)$ \\
Fluoxetine + citalopram & $68(3.3)$ \\
Fluoxetine + paroxetine & $33(1.6)$ \\
Citalopram + sertraline & $22(1.0)$ \\
Fluoxetine + sertraline & $22(1.0)$ \\
Fluoxetine + escitalopram & $16(0.8)$ \\
Sertraline + escitalopram & $9(0.4)$ \\
Citalopram + paroxetine & $8(0.4)$ \\
Citalopram + escitalopram & $6(0.3)$ \\
Paroxetine + sertraline & $4(0.2)$ \\
Fluvoxamine & $3(0.1)$ \\
Fluoxetine + citalopram + sertraline & $2(0.1)$ \\
Fluoxetine + sertraline + escitalopram & $1(0)$ \\
Fluoxetine + citalopram + paroxetine & $1(0)$ \\
\hline
\end{tabular}

30 days before conception and 1.0 (95\% CI: 0.5-1.9) for use in the second or third trimester. We also found no increased risk associated with use of non-SSRI antidepressants in early pregnancy $(\mathrm{OR}=0.5 ; 95 \% \mathrm{CI}: 0.2-1.1)$.

\section{SSRI use and congenital cardiac malformations}

The prevalence of congenital cardiac malformations recorded during the first year of life was $1.3 \%$ among infants born to mothers who redeemed a SSRI prescription in early pregnancy and $0.7 \%$ among infants born to unexposed mothers (Table 1). The adjusted OR for congenital cardiac malformations associated with SSRI use in early pregnancy overall was 1.7 (95\% CI: 1.1-2.5) (Table 4). When we restricted the analysis to firstborn infants only, the adjusted OR was 1.5 (95\% CI: 0.8-2.9). Also, when we extended the follow-up period and examined the risk of cardiac malformations diagnosed within the first three years of life, the OR increased similarly (OR $=1.5 ; 95 \% \mathrm{CI}: 1.0-2.3)$.

In total, 362 infants had a diagnosis of cardiac malformations and heart surgery, or catheter-based therapeutic interventions performed during their first year of life; of these, nine were infants born to mothers who redeemed a SSRI prescription in early pregnancy. After we restricted the outcome to infants who had cardiac malformations, heart surgery, or catheter-based therapeutic interventions performed, the adjusted OR was 2.3 (95\% CI: 1.1-4.6).

Except for paroxetine, use of individual SSRIs were all associated with increased risks of cardiac malformations but our estimates were imprecise (Table 4). Notably, sertraline was associated with a threefold increased risk of cardiac malformations $(\mathrm{OR}=3.0 ; 95 \% \mathrm{CI}: 1.4-6.4)$. The associations between SSRI use overall and septal defects was 1.4 (95\% CI: 0.8-2.3). In the analysis restricted to septal defects among firstborn infants only, the OR was 1.0 (95\% CI: 0.4-2.3). Among the individual SSRIs, we found increased risk for septal defects associated with sertraline ( $\mathrm{OR}=3.3$; 95\% CI: 1.5-7.5) (Table 4).

\section{Discussion}

In this population-based study of more than 2,000 exposed pregnancies, we found that overall maternal use of SSRIs in early pregnancy was associated with a 1.7 -fold increased risk of congenital cardiac malformations. Septal heart defects were the most frequently recorded malformations among infants of exposed women, with sertraline associated with a threefold increased risk of such defects. However, the absolute prevalences were small.

Table 3 Number of exposed (prevalence among exposed) infants with any malformation, noncardiac malformation, cardiac malformation, and septal heart defects according to maternal use of different types of antidepressants ${ }^{\mathrm{a}}$

\begin{tabular}{|c|c|c|c|c|c|}
\hline & $\begin{array}{l}\text { Total number } \\
\text { of exposed }\end{array}$ & $\begin{array}{l}\text { Any malformation } \\
\text { n (\%) }\end{array}$ & $\begin{array}{l}\text { Noncardiac } \\
\text { malformations n (\%) }\end{array}$ & $\begin{array}{l}\text { Cardiac } \\
\text { malformations n (\%) }\end{array}$ & $\begin{array}{l}\text { Septal heart } \\
\text { defects n (\%) }\end{array}$ \\
\hline Any SSRI & 2,062 & $105(5.1)$ & $79(3.8)$ & $26(1.3)$ & $18(0.9)$ \\
\hline Fluoxetine only & 472 & $22(4.7)$ & $16(3.4)$ & $6(1.3)$ & $4(0.9)$ \\
\hline Sertraline only & 352 & $19(5.4)$ & $12(3.4)$ & $7(2.0)$ & $6(1.7)$ \\
\hline Paroxetine only & 297 & II (3.7) & $10(3.4)$ & $\mathrm{I}(0.3)$ & $\mathrm{I}(0.3)$ \\
\hline Citalopram only & 658 & $36(5.5)$ & $30(4.6)$ & $6(0.9)$ & $2(0.3)$ \\
\hline Escitalopram only & 88 & $8(9.1)$ & $5(5.7)$ & $3(3.4)$ & $3(3.4)$ \\
\hline $\begin{array}{l}\text { Non-SSRI } \\
\text { antidepressants }\end{array}$ & 358 & $6(1.7)$ & $6(1.7)$ & $0(0.0)$ & $0(0.0)$ \\
\hline
\end{tabular}

Notes: ${ }^{\mathrm{T}}$ Three women used fluvoxamine only and their infants had no malformations registered; ${ }^{\mathrm{b}}$ Exclusive combinations with non-SSRI antidepressants. 
Table 4 Adjusted odds ratios and 95\% confidence intervals for overall and individual (SSRIs) in relation to congenital malformations

\begin{tabular}{|c|c|c|c|c|c|c|c|}
\hline Outcome & Any SSRI & $\begin{array}{l}\text { Fluoxetine } \\
\text { only }\end{array}$ & $\begin{array}{l}\text { Sertraline } \\
\text { only }\end{array}$ & $\begin{array}{l}\text { Paroxetine } \\
\text { only }\end{array}$ & $\begin{array}{l}\text { Citalopram } \\
\text { only }\end{array}$ & $\begin{array}{l}\text { Escitalopram } \\
\text { only }\end{array}$ & $\begin{array}{l}\text { Non-SSRI } \\
\text { antidepressant }\end{array}$ \\
\hline \multicolumn{8}{|c|}{ Adjusted odds ratio ( $95 \%$ confidence interval) } \\
\hline Any malformation & $1.3(1.1-1.6)$ & $\mathrm{I} .3(0.8-2.0)$ & $1.4(0.9-2.3)$ & I.I (0.6-1.9) & $1.4(1.0-2.0)$ & $2.3(1.0-4.9)$ & $0.5(0.2-I . I)$ \\
\hline $\begin{array}{l}\text { Noncardiac } \\
\text { malformations }\end{array}$ & $1.2(1.0-1.6)$ & I.I (0.7-I.9) & $1.0(0.5-1.9)$ & $1.2(0.6-2.2)$ & $1.4(1.0-2.1)$ & $2.0(0.8-4.9)$ & $0.6(0.3-1.3)$ \\
\hline $\begin{array}{l}\text { Cardiac } \\
\text { malformations }\end{array}$ & $1.7(1.1-2.5)$ & $1.9(0.8-4.3)$ & $3.0(1.4-6.4)$ & $0.5(0.1-3.6)$ & I.I (0.5-2.7) & $3.3(0.8-13.4)$ & - \\
\hline $\begin{array}{l}\text { Septal heart } \\
\text { defects }\end{array}$ & $1.4(0.8-2.3)$ & $1.6(0.6-4.4)$ & $3.3(1.5-7.5)$ & $0.7(0.1-4.6)$ & $0.3(0.0-2.1)$ & $4.2(1.0-17.1)$ & - \\
\hline
\end{tabular}

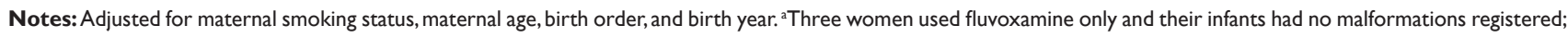
'Exclusive combinations with non-SSRI antidepressants.

Abbreviation: SSRI, selective serotonin-reuptake inhibitor.

Our finding of an elevated risk of septal defects associated with sertraline use agrees with two recent studies. ${ }^{16,19}$ In a US case-control study based on data from the Slone Epidemiology Center Birth Defects Study, Louik and colleagues found a twofold increased risk of septal defects (95\% CI: 1.2-4.0) associated with first-trimester use of sertraline but not with other specific SSRIs. ${ }^{19}$ Exposure information was collected through interviews of mothers with the attendant risk of recall bias. Recently, Petersen and colleagues reported increased risk of septal defects associated with maternal use of sertraline (OR $=3.3 ; 95 \%$ CI: $1.2-8.8)$ and citalopram (OR $=2.5 ; 95 \% \mathrm{CI}: 1.0-6.1)$ in a Danish cohort study. ${ }^{16}$ The authors also found a positive but imprecisely measured association between flouxetine and septal defects ( $\mathrm{OR}=1.34$; 95\% CI: 0.3-5.4). The effect of the newer SSRI escitalopram was not examined. Our data are from the same registers as those used by Pedersen and colleagues,${ }^{16}$ however, the study by Pedersen and colleagues was based on nationwide registries and included children born in Denmark between 1996 and 2003.

In contrast with a meta-analyses based on pre-2006 research, ${ }^{18}$ we found no association between maternal paroxetine use and cardiac malformations. However, the wide CIs of our paroxetine estimates suggest that this finding could be due to chance.

We found a slightly increased risk of malformations overall associated with SSRI use. However, the malformations encompassed 104 different hospital diagnoses, which suggests that the increased risk of malformations overall could be explained by detection bias rather than a causal association. Most previous studies did not find that maternal SSRI use increased the overall risk of congenital malformations. ${ }^{11-17}$

The strengths of our study include its populationbased design, adjustment for important confounders, and complete follow-up for congenital malformations. Use of routinely recorded health care data collected independently of the study hypothesis reduced the risk of information bias.

The validity of our estimates is dependent on the quality of diagnoses of congenital malformations and on the quality of data on SSRI exposure. Despite inevitable coding errors, in Denmark the estimated positive predictive value is $88 \%$ (95\% CI: $86 \%-91 \%$ ) for hospital diagnoses of congenital malformations overall ${ }^{27}$ and $89 \%$ (95\% CI: $86 \%-92 \%$ ) for cardiac malformations. ${ }^{30}$ Any coding errors affecting malformation diagnoses are unlikely to be related to prescribing of SSRIs and would therefore lead to an underestimation of the relative risk. However, detection bias, in which the mothers being treated for depression are more likely to receive or seek out more comprehensive prenatal and postnatal testing of their infants may lead to more complete detection and registration of the less severe congenital malformations. ${ }^{31}$ Moreover, infants born of women using SSRI have an increased risk of neonatal distress, ${ }^{7}$ which may lead to neonatal hospitalization and thus increase the risk of detection of mild cardiac defects that may otherwise remain unnoticed until later in life. Such bias would cause overestimation of the relative risk associated with the use of SSRIs. However, when we restricted the analysis to the more severe cases, ie, infants who had heart surgery/catheter-based therapeutic interventions performed, we also found a positive association.

Another concern is that we used population-based data on malformations recorded during the first year of life, but did not consider malformations leading to a miscarriage or to an elective abortion after prenatal diagnosis. ${ }^{9}$ However, if SSRI use increased the risk of malformation-related miscarriage/ elective abortion, the association between SSRI use and risk 
of malformations would have been underestimated and thus would not alter our conclusions.

Another issue is that redemption of SSRI prescriptions is an imperfect surrogate for SSRI use and we lacked specific information on compliance. We assume high compliance as the prescriptions were picked up at the pharmacy and paid for in part by the patient. Still, we do not know if the women actually took the SSRIs. Nevertheless, such misclassification of SSRI use would likely bias the results toward the null.

Yet another concern is that our exposure window was wide and we did not know the exact exposure time. We therefore conducted an analysis for women who redeemed prescriptions during the second and third month of pregnancy, when organogenesis mainly occurs. ${ }^{9}$ Restricting the exposure period to this time interval did not appreciably change the estimates for SSRI use overall.

As well, we cannot exclude the possibility that increased risk of congenital malformations is caused by the disease underlying SSRI use or by other disease-related factors, rather than by SSRI use itself. ${ }^{9}$ Nevertheless, we found no increased risk of congenital malformations overall among women using other antidepressants, among previous SSRI users, or among women exposed to SSRIs during late pregnancy.

The higher risk estimates associated with use of specific SSRIs could be due to chance or confounding by indication, if these drugs were prescribed to women with more severe depression. In a meta-analysis of 117 randomized controlled trials conducted from 1991 to $2007,{ }^{32}$ sertraline and escitalopram were found to be more efficacious than fluoxetine in terms of response. These drugs may be prescribed more frequently to women whose severe depression requires a rapid treatment response. However, like most previous studies on this topic, we were unable to control for maternal disease type and severity. Finally, despite the relative large size of our study overall, we had limited power to evaluate associations between specific SSRIs and specific congenital malformation such as anencephaly, omphalocele, and craniosynostosis.

In conclusion, we found little overall association between use of SSRIs during pregnancy and congenital malformations, but our findings suggest an association between maternal SSRI use in early pregnancy and cardiac malformations which could be causal.

\section{Acknowledgments}

The study was supported by an unrestricted research grant from $\mathrm{H}$ Lundbeck A/S. The authors report no conflicts of interest in this work.

\section{References}

1. Ververs T, Kaasenbrood H, Visser G, Schobben F, de Jong-van den Berg, Egberts T. Prevalence and patterns of antidepressant drug use during pregnancy. Eur J Clin Pharmacol. 2006;62(10):863-870.

2. Andrade SE, Raebel MA, Brown J, et al. Use of antidepressant medications during pregnancy: a multisite study. Am J Obstet Gynecol. 2008;198(2):194-195.

3. Cooper WO, Willy ME, Pont SJ, Ray WA. Increasing use of antidepressants in pregnancy. Am J Obstet Gynecol. 2007;196(6):544-545.

4. Bakker MK, Kolling P, van den Berg PB, de Walle HE, de Jong van den Berg LT. Increase in use of selective serotonin reuptake inhibitors in pregnancy during the last decade, a population-based cohort study from the Netherlands. Br J Clin Pharmacol. 2008;65(4):600-606.

5. Hendrick V, Stowe ZN, Altshuler LL, Hwang S, Lee E, Haynes D. Placental passage of antidepressant medications. Am J Psychiatry. 2003;160(5):993-936.

6. Rampono J, Simmer K, Ilett KF, et al. Placental transfer of SSRI and SNRI antidepressants and effects on the neonate. Pharmacopsychiatry. 2009;42(3):95-100.

7. Alwan S, Friedman JM. Safety of selective serotonin reuptake inhibitors in pregnancy. CNS Drugs. 2009;23(6):493-509.

8. Berard A, Ramos E, Rey E, Blais L, St-Andre M, Oraichi D. First trimester exposure to paroxetine and risk of cardiac malformations in infants: the importance of dosage. Birth Defects Res B Dev Reprod Toxicol. 2007;80(1):18-27.

9. Wogelius P, Nørgaard M, Gislum M, et al. Maternal use of selective serotonin reuptake inhibitors and risk of congenital malformations. Epidemiology. 2006;17(6):701-704.

10. Cole JA, Ephross SA, Cosmatos IS, Walker AM. Paroxetine in the first trimester and the prevalence of congenital malformations. Pharmacoepidemiol Drug Saf. 2007;16(10):1075-1085.

11. Davis RL, Rubanowice D, McPhillips H, et al. Risks of congenital malformations and perinatal events among infants exposed to antidepressant medications during pregnancy. Pharmacoepidemiol Drug Saf. 2007;16(10):1086-1094.

12. Kallen BA, Otterblad OP. Maternal use of selective serotonin re-uptake inhibitors in early pregnancy and infant congenital malformations. Birth Defects Res A Clin Mol Teratol. 2007;79(4):301-308.

13. Kulin NA, Pastuszak A, Sage SR, et al. Pregnancy outcome following maternal use of the new selective serotonin reuptake inhibitors: a prospective controlled multicenter study. JAMA. 1998;279(8):609-610.

14. Malm H, Klaukka T, Neuvonen PJ. Risks associated with selective serotonin reuptake inhibitors in pregnancy. Obstet Gynecol. 2005;106(6):1289-1296.

15. Pastuszak A, Schick-Boschetto B, Zuber C, et al. Pregnancy outcome following first-trimester exposure to fluoxetine (Prozac). JAMA. 1993;269(17):2246-2248.

16. Pedersen LH, Henriksen TB, Vestergaard M, Olsen J, Bech BH. Selective serotonin reuptake inhibitors in pregnancy and congenital malformations: population based cohort study. BMJ. 2009;339:b3569.

17. Simon GE, Cunningham ML, Davis RL. Outcomes of prenatal antidepressant exposure. Am J Psychiatry. 2002;159(12):2055-2061.

18. Bar-Oz B, Einarson T, Einarson A, et al. Paroxetine and congenital malformations: meta-Analysis and consideration of potential confounding factors. Clin Ther. 2007;29(5):918-926.

19. Louik C, Lin AE, Werler MM, Hernandez-Diaz S, Mitchell AA. Firsttrimester use of selective serotonin-reuptake inhibitors and the risk of birth defects. N Engl J Med. 2007;356(26):2675-2683.

20. Oberlander TF, Warburton W, Misri S, Riggs W, Aghajanian J, Hertzman C. Major congenital malformations following prenatal exposure to serotonin reuptake inhibitors and benzodiazepines using population-based health data. Birth Defects Res B Dev Reprod Toxicol. 2008;83(1):68-76.

21. Diav-Citrin O, Shechtman S, Weinbaum D, et al. Paroxetine and fluoxetine in pregnancy: a prospective, multicentre, controlled, observational study. Br J Clin Pharmacol. 2008;66(5):695-705. 
22. Alwan S, Reefhuis J, Rasmussen SA, Olney RS, Friedman JM. Use of selective serotonin-reuptake inhibitors in pregnancy and the risk of birth defects. N Engl J Med. 2007;356(26):2684-2692.

23. Hiemke C, Hartter S. Pharmacokinetics of selective serotonin reuptake inhibitors. Pharmacol Ther. 2000;85(1):11-28.

24. Deave T, Heron J, Evans J, Emond A. The impact of maternal depression in pregnancy on early child development. BJOG. 2008;115(8): 1043-1051.

25. Orr ST, Miller CA. Maternal depressive symptoms and the risk of poor pregnancy outcome. Review of the literature and preliminary findings. Epidemiol Rev. 1995;17(1):165-171.

26. Knudsen LB, Olsen J. The Danish Medical Birth Registry. Dan Med Bull. 1998;45(3):320-323.

27. Larsen H, Nielsen GL, Bendsen J, Flint C, Olsen J, Sørensen HT. Predictive value and completeness of the registration of congenital abnormalities in three Danish population-based registries. Scand $J$ Public Health. 2003;31(1):12-16.
28. Fonager K, Larsen H, Pedersen L, Sørensen HT. Birth outcomes in women exposed to anticonvulsant drugs. Acta Neurol Scand. 2000;101(5):289-294.

29. Nielsen GL, Nørgard B, Puho E, Rothman KJ, Sørensen HT, Czeizel AE. Risk of specific congenital abnormalities in offspring of women with diabetes. Diabet Med. 2005;22(6):693-696.

30. Jepsen B, Jepsen P, Johnsen SP, Espersen GT, Sørensen HT. Validity of diagnoses of cardiac malformations in a Danish population-based hospital-discharge registry. Int J Risk Saf Med. 2006;18(2):77-81.

31. Chambers C. Selective serotonin reuptake inhibitors and congenital malformations. BMJ. 2009;339:b3525.

32. Cipriani A, Furukawa TA, Salanti G, et al. Comparative efficacy and acceptability of 12 new-generation antidepressants: a multipletreatments meta-analysis. Lancet. 2009;373(9665):746-758.
Clinical Epidemiology

\section{Publish your work in this journal}

Clinical Epidemiology is an international, peer-reviewed, open access journal focusing on disease and drug epidemiology, identification of risk factors and screening procedures to develop optimal preventative initiatives and programs. Specific topics include: diagnosis, prognosis, treatment, screening, prevention, risk factor modification, systematic

\section{Dovepress}

reviews, risk \& safety of medical interventions, epidemiology \& biostatical methods, evaluation of guidelines, translational medicine, health policies \& economic evaluations. The manuscript management system is completely online and includes a very quick and fair peer-review system, which is all easy to use. 